\title{
article
}

\section{The 'Milky Way' of intermediary organisations: a transnational field of university governance}

\author{
Kerstin Sahlin, Uppsala University; Kerstin.Sahlin@fek.uu.se \\ Filip Wijkström, Stockholm School of Economics, Filip.Wiljkstrom@hhs.se; \\ Lisa Dellmuth, Stockholm University, Lisa.Dellmuth@statsvet.su.se; \\ Torbjörn Einarsson, Stockholm School of Economics, \\ Torbjorn.Einarssom@hhs.se; \\ Achim Oberg, University of Mannheim/Wirtschaftsuniversität, \\ oberg@ifm.uni-mannheim.se ${ }^{1}$
}

\begin{abstract}
This article focuses on transnational intermediary organizations in higher education and research We conceive of intermediaries as organizations that are actively involved in transnational university governance without having formal access to or control over policy or governmental funding. Such intermediary organizations have in previous research been shown to play central roles in the development and circulation of new themes and ideas for how to manage universities and measure university performance. Intermediaries link different types of actors and act as translators of global themes. In this respect, they are decisive in policy formulation.
\end{abstract}

keywords: intermediary organisations $\cdot$ university $\cdot$ transnational $\cdot$ governance

\section{A transnational network of university governance}

In recent decades, we have witnessed a profound transformation of what is now commonly perceived to be a global university field (for example, Drori et al, 2012; Frank and Meyer, 2007). Universities are typically governed and financed within national systems of higher education and they differ widely in terms of type (for example, private or public) and funding structure. The governing, performance monitoring, and organisation of universities varies considerably locally yet follows global themes (Ramirez, 2010; Hedmo et al, 2006; Sahlin, 2013). Furthermore, the wider global university field is shaped by transnational networks and collaborative arenas of governance (see Beech, 2009; 2011; Maasen and Olsen, 2007; Ramirez, 2012; Krücken and Meier, 2006): a growing number of transnational intermediary organisations form important arenas for actors from different countries that compare and assess universities, and form as well as translate ideas for how to manage universities and measure university performance (for example, Sahlin, 2013). This article focuses on the role and position of transnational intermediary organisations. Typically, those intermediary organisations are actively involved in transnational university governance without having formal access to or control over policy or governmental funding. Intermediaries can be placed, analytically, between those who aim to govern and 
those who are governed. In this position, these organisations function as organisational bridges between these two different communities. This article conceptualises transnational intermediaries and provides systematic empirical evidence for the importance of intermediaries in the scaling up of collaborative governance.

The growing importance and complexity of transnational governance has received increased scholarly attention during the last decade. Especially since the end of the cold war, the diversity of actors involved in global governance has increased, ranging from multinational corporations, professional associations, to non-governmental organisations (NGOs). These actors differ widely in terms of functions. Broadly speaking, they 'create issues, set agendas, establish and implement rules or programs, and evaluate and/or adjudicate outcomes' (Avant et al, 2010,10). Moreover, transnational governance is highly organised (Drori et al, 2009, 17). Organisations have emerged and risen in both number and activity worldwide to the extent that our contemporary society has been described as 'the organised society' (Perrow, 1991; 2002; see also Meyer and Bromley, 2013). Particularly noteworthy is the continuous growth of international organisations (for example, Boli and Thomas, 1997; Drori et al, 2009). This is especially true for international non-governmental organisations, whose members largely comprise a mix of governmental units, corporations and NGOs and various nonprofit and voluntary associations (for example, Tallberg et al, 2013). Transnational governance also tends to be organised in the sense that the links and relations among those many and different organisations are largely organised in the form of transnational networks (Torfing, 2012; Marcussen and Torfing, 2007).

Transnational networks transcend national boundaries, even if governmental bodies and intergovernmental bodies constitute important parts of those networks. A defining characteristic of transnational networks is, as argued by Djelic and Sahlin (2011), the blurring of the distinction between national and international, governmental and non-governmental, public and private. This blurring of boundaries between sectors was identified by Stoker (1998) who identified as a defining characteristic for our understanding of governance, as there is a 'baseline agreement that governance refers to the development of governing styles in which boundaries between and within public and private sectors have become blurred' (Stoker, 1998,17). In this way, transnational networks form core parts of a mode of governance that relies on mechanisms not directly associated with state authority or sanctioning power (see also Risse, 2012). Not only actors and organisational boundaries, but also modes and mechanisms of governing tend to be blurred and to rely on combinations of authorities. Such modes of governance have been shown to follow complex patterns of an interplay between soft and hard law (Mörth, 2004) and between ideational norms and financial measures (Avant et al, 2010; Finnemore and Sikkink, 1998), and of the linking between rules, to each other, to organising and to expertise (Djelic and Sahlin-Andersson 2006).

In this article we used a web-crawler technique to map transnational intermediaries concerned with higher education and research, and their linkages with each other.We created an original data set of more than 400 intermediary organisations active in the global university field during 2014. Based on network analysis of these data, we argue that these transnational intermediaries form an organised field of their own, where actors are attuned to and interact with each other based on a shared understanding of the field, its rules and actors as well as agreement among the actors of what is at stake. This implies that they together perform important roles in the travelling and translation of global themes for how to govern and define universities, and that they 
are crucial for the scaling up of transnational collaborative governance. Against the backdrop of existing literature, the broader purpose of our analysis is to open up an agenda for the future study of fields of transnational intermediaries.

The remainder of this article proceeds as follows. The ensuing section develops a conceptualisation of intermediary organisations. The following section briefly describes the globalised university landscape and the importance of and interactions between transnational intermediaries by drawing on previous studies about the globalised university field. We then present the analytical framework of organised fields, followed by an account of the methods applied in this project, and the empirical results. The concluding section expands on the broader implications of our empirical results for existing research on transnational networks and future research on intermediaries in collaborative governance.

\section{Transnational intermediaries}

Previous studies have highlighted a large array of normative and ideational functions of different types international organisations, pertaining to the diffusion of norms and ideas (Boli and Thomas, 1997; 1999; Finnemore, 1993; Finnemore and Sikkink, 1998; Reuter et al, 2014; Marcussen, 2000; 2004; Brunsson and Jacobsson 2000). International organisations largely reflect what is happening in a particular field, but they also shape and disseminate ideas and conceptualisations, establish and strengthen core institutions and they are important meeting places of the field. John Meyer has used the term 'others' to describe the features and functions of these organisations, paving the way for research on such organisations and their role in processes of idea circulation and transnational governance:

Others, in this scheme loosely derived from George Herbert Mead, do not take action responsibility for organisational behavior and outcomes. They discuss, interpret, advise, suggest, codify, and sometimes pronounce and legislate. They develop, promulgate, and certify some ideas as proper reforms, and ignore and stigmatise other ideas. Who are these Others, and why are there so many of them, out there in the modern organisational environment? (Meyer, 1996, 244)

Subsequent studies built on Meyer's distinction and focused on those kinds of 'otherorganisations' and on their role in transnational governance, and in the circulation of ideas. Terminology, however, has shifted. Such organisations have been termed 'carriers', in analyses of how they promote and circulate management ideas (Sahlin-Andersson and Engwall, 2002), and 'editors', in analyses of how they not only promulgate, certify and circulate ideas, but also how they edit those ideas as they circulate them (SahlinAndersson, 1996; Sahlin and Wedlin, 2008). The role of such organisations in the transfer, translation and editorial work has also been noted in research on university governance (for example, Beech, 2011; Sahlin and Wedlin, 2008; Drori et al, 2012).

Terminologies differ, but a common result from the above cited studies is that organisations that circulate, edit and mediate ideas are important in the formation of organised fields and in governance. We conceive of such organisations as intermediary organisations. The conceputalisation as intermediaries emphasises these organisations' spanning function and their role in bringing together and scaling up collaborative 
governance and networks (for a similar argument in global environmental governance, see Andonova and Mitchell, 2010).

Based on the previous research cited above, we argue that many transnational organisations play important roles as intermediaries: they develop ideas and norms; span organisational and national boundaries; and develop more globalised and rationalised cultures of university governance and university development. Through a better understanding of these organisations' roles and relationships with each other as well as other actors we can understand the governance dynamics in the wider, globalised university field.Yet previous works have been predominantly qualitative case studies of specific actors, global themes, or the growth of international organisations, failing to provide systematic knowledge about who these actors are and how they are linked to each other.

Intermediaries do not control or make ultimate decisions about policy, such as the allocation of resources or the shaping of legal frameworks. Neither do they possess the formal authority to compel compliance with different forms of regulatory systems. Rather, intermediaries function as organisational arenas in the transnational networks of university governance, bridging governing actors and governed institutions. Intermediary organisations also represent and develop various interests with stakes in the transnational governance network, that is, they are actors in their own interest and capacity. These interests may be rooted in the values or interests of the members or constituencies of the individual intermediary, yet intermediary organisations can also be expected to develop an interest in their own organisational survival, growth and position in the field.

An old observation in organisation theory is that organisations tend to develop an interest in their own survival and growth (for example, Selznick, 1949), and stabilise and formalise over time. Studies of intermediary organisations in the particular area of business schools have clearly shown that such dynamics are at play and partly explain some of the recent expansion of evaluation and monitoring schemes (Hedmo, 2004; Hedmo et al, 2006). These observations suggest that organisational activities and relations among intermediaries form important dynamics in the transnational governance of universities. Traditional examples of intermediaries in the university field are intergovernmental organisations; academic associations; assessing, ranking and accreditation agencies; think tanks, university networks and umbrella organisations consisting of, created by and for universities; and associations of industry, student and professional interests. These organisations are increasingly hybrid in their character as they cross and span different societal spheres and combine as well as merge those sector logics; that is, civil society, the private and public sectors (see Wijkström, 2011) and they also form boundary spanners across these societal sectors (see Hedmo and Sahlin-Andersson, 2006).

\section{A global university landscape in transition}

Universities worldwide have been reorganised in terms of organisation and management, largely inspired by globally diffused ideas. Extended demands are put on higher education and research to contribute to policy and to innovation and growth. The latter are concepts that are increasingly used by many national governments. This development has analytically been described in terms of universities having become increasingly rationalised at the same time as they are being increasingly embedded 
in society (for example, Ramirez, 2006; 2010; see also Maasen and Olsen, 2007). Global debates also show an increased demand for academic excellence, and 'blue sky' research, with intermediary organisations playing a crucial role for the diffusion of related ideas. We use these examples to illustrate that global themes and ideas on university governance are far from coherent and unidirectional.

The described developments are global in scope, and indeed, one of the most important transformations of the entire landscape of higher education and research is its increased degree of transnationalisation. Universities have of course from the very beginning worked in a highly global context and partly also been governed and controlled by a global regulatory framework. Today, however, new global themes of organising, governing and performance measurements largely transform the conditions for research and higher education in a more systematic and profound way. The on-going transnationalisation of the university landscape is influenced by widely circulated themes.

One such global theme that has evolved and circulated globally is that of university rankings. Studies of this global theme show the importance of a multitude of transnational intermediaries for spreading those ideas and ideals (see Sahlin, 2013). Rankings have come to be part of the broader frame of governance of universities and have at the same time spurred extensive organising efforts, among individual universities as well as among and between intermediary organisations. The spread of rankings have certainly been pursued by a multitude of interlinked intermediaries, and with this development intermediary organisations have developed links with each other.

\section{Field models in organisational analysis}

In the previous sections, we referred to previous research showing that intermediary organisations are crucial in transnational governance networks. Apart from having close linkages with those aiming to govern and those who are governed, intermediaries are connected with each other in many different ways. They compete with each other, but also collaborate and they imitate each other. This leads us to expect that the importance of intermediary organisations is largely due to interlinkages among them. With such dense linkages among intermediaries, they can be expected to form a recognisable field of their own.

What, then, is a field? How can it be conceptualised and mapped? Field models have a long history in the social sciences, although with slightly different emphasis in different traditions and disciplines (Lewin, 1951; Bourdieu, 1977; 1984; Meyer and Rowan, 1977; DiMaggio and Powell, 1983).A more strategic approach to organised fields has recently been developed by Fligstein and McAdam $(2011 ; 2012)$ in their work on 'strategic action fields'.

Following Martin's (2003) and Mohr's (2005) overviews of field models in social sciences, Djelic and Sahlin-Andersson (2006) noted that in practice, many studies tend to reduce fields to networks of actors and interactions. However, field models typically emphasise that fields involve structured patterns of interaction as well as a meaning dimension - common beliefs in the importance of certain activities and a mutual awareness of what is at stake. Moreover, as emphasised by DiMaggio and Powell $(1983,148)$ 'The structure of an organisational field cannot be determined a priori but must be defined on the basis of empirical investigation.' 
Building on this definition of a field, the following sections of this article analyse the field of transnational university governance intermediaries empirically. Our working hypothesis is that a large number of intermediary organisations is active in university governance, forming a recognisable organised field of their own, where the organisations are attuned to and interact with each other based on a shared understanding of this particular field, its rules and actors as well as a kind of agreement among the actors of what is at stake. Within this intense exchange, we also expect an active global circulation of norms, themes and ideas, with implications for national university systems and individual universities.

\section{The empirical study}

To map the transnational intermediaries and their linkages with each other, we use an original web-crawler technique. Using this technique, we map the links between websites of intermediaries. Such links can indicate interactions as well as mutual awareness and referencing. Hence, mapping their connections encompasses both aspects of field models - meaning and interaction.

To identify the population of intermediaries active in transnational university governance, we compiled a data set on organisations from a combination of sources. Our data collection strategy proceeded in several steps. To begin with, we derived data on 82 organisations defined as active in what is described as 'higher education' in the Yearbook of international organizations (Union of International Associations, 2014). The Yearbook is the largest and most encompassing catalogue of international organisations to date. The list of these 82 organisations encompasses active organisations that are not subsidiary or internal bodies of other international organisations.

This catalogue, however, does not capture all the organisations active in global university governance that we are seeking. To identify the population of intermediaries, we therefore used the list of organisations identified through theYearbook as a starting point for a second-level mapping that relied on an iterative combination of a webcrawling technique and extensive manual data cleaning. Using this technique, we identified organisations through existing links on the web pages of the set of the 82 already identified organisations (the so-called 'seed' organisations) to web pages of other organisations. This snowballing technique is based on the assumption that the links that the 82 'seed' organisations provide on their web pages to other organisations' web pages are indicators for interaction and recognition between these organisations, thereby identifying other relevant organisations in the population. We ran the webcrawler and received a set of 19,795 domains referenced by the seed organisations.

In order to reduce the amount of irrelevant domains that are characterised by weak recognition by other organisations in the field, a cut-off limit of at least four incoming links to the domain were used in order for a new organisation to be included in the material. This resulted in a total list of 2,915 web domains, for which the webpages were analysed for signs of any kind of intermediary function at transnational level. This list included domains owned by intermediaries and other organisations in the university field, that is, close to our target group, but the list also contained many domains belonging to other types of organisations and different forms of web services, such as Facebook and Google. We manually inspected and evaluated each of the 2,915 candidate domains and kept only those 654 domains belonging to an organisation with a distinct relation to higher education or research and an indication of some 
kind of intermediary function. The purpose of the manual sorting and cleaning of the results yielded by the web-crawling technique was to arrive at a stable valid data set, while simultaneously ensuring a reliable data collection process.

This selection procedure obviously involved judgements regarding where to draw the boundary of the field; below we briefly describe how three such boundary considerations were handled.A first judgement concerned which organisations should be considered to be intermediaries. The majority of organisations on the list are the typical kinds of intermediary organisations as described above; they are actively involved in transnational university governance without having formal access to or control over the funds and legislation in the field. However, all relevant organisations are not single-purpose organisations, but many display a broad palette of functions, roles and activities. The decision was made to include all those organisations that clearly included intermediary functions in their presentations. This meant that the list also includes a limited number of organisations that primarily operate as research funding bodies, such as the British Council,Volkswagenstifung and The German Foundation (DFG). These three organisations can also exemplify boundary judgements of a second type, namely which organisations to define as transnational. Here, our webcrawling process was used as the selection criterion. As described above, we included in the field those intermediary organisations that on their website had at least four links with other organisations in the identified transnational field. A third boundary judgement prescribed which organisations should be considered as included in the field of transnational university governance, as opposed to other fields of society. In this respect, we excluded general domains, such as Facebook and Google, but also included some addresses that were not specific for university governance, such as the World Bank and the Organisation for Economic Co-operation and Development (OECD). Although these latter international organisations are actively involved the university governance field, this is not their only or even primary field of interest as they are also active in other fields (see, for example, Marcussen, 2000; 2004; Avant et al, 2010).

In the final step of the data collection, we ran the web-crawler again for the 654 domains of intermediary organisations to collect all references between these organisations and kept only those organisations whose webpages yield both outgoing and in-going references to and from other actors in the field. Furthermore, we increased the required number of ties to five or more and thus created a core set of 451 intermediary organisations, among which we were able to identify the pattern of linkages and the key players. This data collection strategy resulted in a networked population of intermediaries identified as the primary organisations of the transnational field of university governance.

\section{The transnational field of intermediaries in university governance}

This section presents the empirical results. We briefly describe the identified set of intermediaries and we present maps to display their mutual linkages. These maps, we argue depicts a core network of intermediaries within the field of transnational university governance. 


\section{A variety of organisational types and sectors}

A first finding is that the 451 intermediary organisations in our data set represent a variety of types and that their many constituents come from different sectors in society. In terms of legal and organisational form, most intermediaries are NGOs with voluntary membership. The members or other forms of constituents are primarily either governmental, public agencies or other state bodies or they come from civil society; including interest organisations such as student unions, professional associations, scholarly societies and trade unions. We have identified a few corporations as members, although this is not a major component in our material. We further find a smaller number of intergovernmental organisations and also nationally based organisations with clear transnational agendas. The intermediate organisations are largely hybrid in form as they span different societal sectors, for example, crossing the public-private divide or mediating between state and civil society.

\section{The 'Milky Way' of intermediaries}

The remainder of this section is confined to the mapping and analysis of the linkages among the identified intermediaries. More specifically, our analysis proceeds in three steps. First, we start with the population of 451 well-connected intermediary organisations with web links to other intermediaries on their webpages, where both organisations recognise each other. In total, 1,640 such bi-directional ties were identified within this system, where the size of the node in Figure 1 represents the total number of bi-directional ties for each node or organisation (the average number being 7.27). As described above, the bi-directional links are seen to signify interactions and/ or mutual recognition between the intermediaries. Hence, we understand this network of nodes and ties to portray the core organisations in an organised transnational field of intermediaries. The field has no obvious single centre but instead a set of kept-together organisational constellations, illustrated in the stretched-out structure of the field with several more densely connected cores and some lesser but still well connected satellite organisations in the periphery (see Figure 1). ${ }^{2}$

Our initial analysis indicates a field with a structure resembling a 'Milky Way' in view of the large number of organisations, the diversity in the field and to the intense mutual recognition among the transnationally active university intermediaries. The high number of salient nodes in the pattern illustrates the intensity of mutual recognition among the many organisations in the field. Further, the stretched-out character of the field is due to more complex patterns of recognition among the organisations affecting the internal field structure (see next section).

Among the most recognised organisations in the field, we observe such organisations as the European University Association (EUA), the Academic Cooperation Association, but also an organisation like RePEc (Research Papers in Economics) run by scholars themselves serving as volunteers, and the World Bank (see also Appendix on core intermediaries). These examples illustrate well the spread and diverse character of the intermediaries involved in transnational university governance. 


\section{The core of the field}

The initial analysis (illustrated in Figure 1) contains all 451 organisations that had at least one bidirectional reference to another intermediary organisation. In a second step we decided to increase the required number of bidirectional links to other actors to five or more to enhance the likelihood to identify the core of the field. This new core of the field comprises 243 organisations and the stretched-out Milky Way character is sustained (see Figure 2).

Figure 1: The 'Milky Way' of transnational university intermediaries

Nodes Intermediaries within the largest component $(N=451)$

Relations Bi-directional ties of intermediaries on the WWW $(N=1640)$

Node size Number of bi-directional ties (average degree $=7.27$ )

In total, 1,208 bi-directional relations among these 243 core organisations were identified and the average number of ties has now increased to 9.94 ties (from earlier 7.27). Each organisation thus has several links with others in the field. On the basis of this finding, we argue that these intermediary organisations recognise each other and can be expected to interact with each other. When it comes to the structure of the field, this core population of organisations remains stretched out in the same way as the field as a whole.

\section{A structure of inter-connected sub-clusters}

In a third step we have visualised how the inter-organisational linkages are distributed throughout the field (see Figure 3). With this visual analysis we were able to identify four main clusters containing more densely related and linked organisations. 


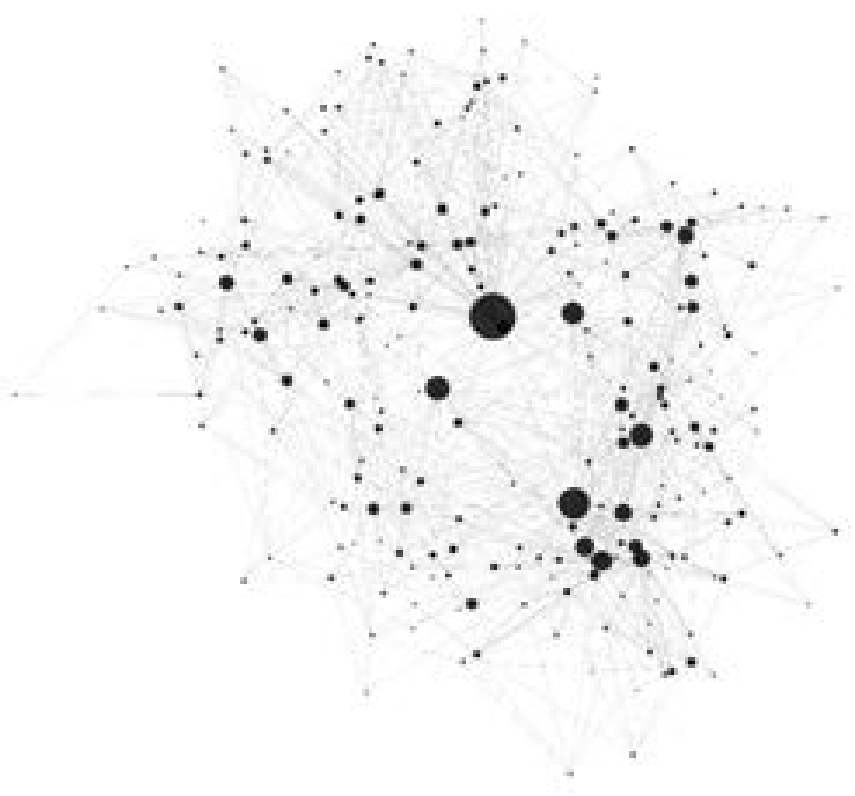

In Figure 3, we can observe the very same 243 intermediaries also displayed in Figure 2, with the same number of ties (and an average of 9.94 ties per node). To enhance the analysis, we have, however, chosen to highlight the four potential clusters in the illustration and also add organisational labels for those of the core organisations that have 15 or more bi-directional ties, thus being even stronger recognised by the other intermediaries and potentially central organisations in the field (for lists of the most central intermediaries for each of the clusters, see Appendix).

Interestingly, we are able to identify fairly distinct features of each such cluster. To begin with, in the south-east/lower-right corner of the figure, we find a cluster where the organisations are centred around the European Union (EU). This is also the intermediary cluster with highest internal density with respect to the number of ties in-between organisations. We find a high degree of Brussels-based intermediaries at the very core of this cluster. Moreover, two of the other clusters contain a large number of organisations based in Europe, whereby one (north-east/upper-right corner) encompasses several organisations primarily based in Germany while the other (south-west/lower-left corner) instead is dominated by UK-based intermediaries. The fourth cluster, finally, resides in the north-west/upper-left corner of the illustration and contains a fair deal of organisations perhaps best described as 'international'. In each of the clusters we are able to identify a number of intermediaries that are more central than the others and the multi-centred structure of the field is thus confirmed. Yet, the four sub-clusters are linked with each other through many linkages and in addition through a handful of intermediaries that link with all four sub-clusters but are themselves rather positioned between them. Among them we find one organisation that stands out in the material and represent something like a mother-hub in the field, namely the World Bank. The World Bank has several different web pages and 
Figure 3: Four clusters in the transnational field of university governance

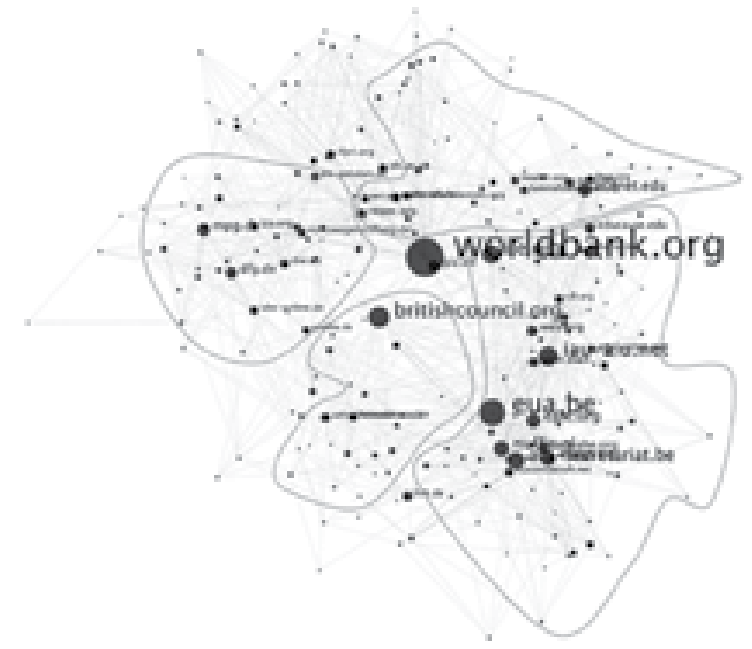

web addresses for different parts or programmes of the organisation, and those were in the project technically merged manually as one single umbrella website for the continued analysis. This particular organisation exhibits a large number of ties with other actors in the field, as indicated by the sheer size of the node in the illustration (see Figure 3). What is more important, however, is that the World Bank cannot easily be subsumed into one or the other cluster through a denser set of ties with a particular cluster. Neither can the World Bank be said to serve as the centre of the field with its still polycentric character. The special position of the organisation as and interlinking node across the clusters in the field is, however, stable as it has more or less equally strong ties with members of all the four identified clusters and it is thus positioned in a unique in-between role potentially bridging the clusters.

\section{Discussion and conclusions}

This article uses the concept of intermediaries to direct our attention to the many organisations that populate the intermediate space between the many actors of the transnational governance field and between those who aim to govern and those who are governed. Intermediaries largely reflect what is happening in the field, but they also shape and disseminate ideas and conceptualisations, establish and strengthen institutions and they are important meeting places and boundary spanners of the field. This article takes the first steps in developing systematic knowledge on the roles and relations of such intermediary organisations, adding new knowledge about intermediary organisations and transnational networks of governance.

To begin with, our literature review showed the importance of intermediaries in disseminating global themes and ideas that shape policies and measures among governing bodies, universities and other research and higher education institutions. Furthermore, previous research has pointed to the expansion of intermediary organisations and their close linkages with each other, leading to the working 
hypothesis that intermediaries form an organised field of their own. To examine this hypothesis empirically, we created a dataset of intermediaries through an original method that builds, first, on primary information on organisations in the Yearbook of international organizations, and, second, identifies web-links to other intermediaries through stepwise web-crawlings.

Our empirical analysis yielded three main findings. First, we found a surprisingly large number of intermediary organisations that operate in the transnational network of university governance. The organisations in our data come in different types and forms, and span various societal sectors, such as civil society and the public sector. Our second finding confirms the working hypothesis that intermediaries are closely linked with each other. We took these links to indicate mutual recognition and interaction among and between the intermediaries. In this respect, intermediary organisations form an organised field of their own. A third finding is that this field exhibits a multi-centred and stretched-out structure, which we refer to as a 'Milky Way' pattern.

When manually scrutinising all websites, we could confirm that most organisations in our dataset are exclusively working with intermediary functions; they evaluate, coordinate, observe and seek to influence policy. However, some are also funding research and performing research themselves, others are clearly operating nationally while some are only partly active in the wider university field. These organisations were included in our dataset as they have sub-domains or exhibit additional roles that more clearly address intermediary functions in the field of transnational university governance.

A combination of continued web-crawlings and more qualitative cases studies of individual organisations and global themes will lead us to increased knowledge of the transnational field of intermediaries, their complex intra-organisational designs and, finally, also about their relations with other actors in transnational networks of governance.

Within this transnational field of intermediaries we identified a number of clusters or groups of organisations, possibly explaining some of the elongated structure of the field. These clusters seem to be geographically determined. Within each of these clusters, we identified a number of organisations with a more central position than the others. Further research will address the question why this is so. Is it simply because it is easier to mingle with nearby friends or are there deeper and more meaningful differences between the clusters? Could it be that the different clusters actually are dealing with or prioritising different issues or do they have different views on certain questions?

One of the clusters was clearly centred around Brussels. In this cluster, organisations can be expected to have close interactions with the European Union (EU), and in fact may be dependent on the EU for resources, legitimacy and attention. This finding points to promising avenues for future research on the development of the European Union and its impact. What is important is that to enhance our understanding of intermediaries, future studies could investigate whether intermediaries strengthen the voice of researchers, universities and professional bodies vis-à-vis the EU and other political institutions. Furthermore, future research could examine when and how intermediaries rather form venues for influence of the European Union and other political bodies. Do intermediaries in other words contribute to an increased politicisation of the university field (see de Wilde and Zürn, 2012; Zürn et al, 2012)? 
Interestingly, a number of organisations in central positions within the field appear, but without an obvious place in any of the identified clusters. They form nodes where sub-clusters of the field are interlinked. This observation indicates a potential structure of transnational governance sub-networks with dense regional clusters, embedded in and interlinked with other regional clusters. The European region is a special case - densely populated by intermediary organisations and many links among them.

This article provides a first glance of the field of transnational intermediaries active in the governance of universities, yet our inquiry is also characterised by limitations that point to potential future research. To begin with, the dataset may exhibit a European bias as the Yearbook of international organizations is Europe-based. We sought to control for this bias through the web-crawling and manual sorting of the lists. However, limitations in terms of mapping the hubs and well as the links between the organisations remain. The European bias inYearbook could still have some importance. Another bias concerns language. We can, for example, assume a number of Asian organisations with non-English websites and references among themselves. Clearly these fall outside our data. Furthermore, we cannot see ties that may develop 'under the radar' and informally without being reflected in links on the websites. Moreover, certain organisations might rather link to their 'preferred partners' in the field only, while just writing the names of (or completely omit mentioning) organisations with which they do not share the same ideas or even are in conflict, thus running the risk of reducing the field to only the like-minded. If this would be carried out systematically throughout the field, even with a relevant original set of organisations to start with, it would result in several clusters in the relevant 'web-crawler universe' without any ties in-between the clusters. These limitations suggest that future research would need to develop with extended web-crawling combined with qualitative studies of individual organisations, clusters and global themes.

We conclude by pointing at how our data set can be developed to explore four additional questions that follow from the cited literature on intermediaries, organised fields and transnational governance. First, previous studies have indicated an almost exponential growth of international non-governmental organisations, many of which we have defined to be pursuing intermediary functions. In subsequent work, we will be able to add more dynamic data to our dataset, most immediately by adding dates of when the different organisations in the field were founded. Second, studies of global governance have shown the multitude and diverse sets of actors involved in global governance. By coding our data according to type of actor and type of activities in which they involve, further empirical research will systematically show this diversity and also be able to map the hybridity of the field. Of specific interest will be to study the existing private-public links and overlaps in this particular field in more detail, not least related to ongoing discussions and research on the many aspects of privatisation of higher education and research. And last, one main background to this paper was our interest in global themes that permeate and shape university governance. Using the web-crawling technique, we have collected all material available at the official websites, which means that we can search for specific words, key phrases and particular references other than links to the domains of other organisations. Through the mapping and analysis of the conceptual patterns created by the tracking of such key terms and phrases and the trajectories of them throughout the field of transnational intermediaries, we can empirically map and more clearly 
understand the emergence, circulation, clustering and travels of global themes in the transnational field of university governance.

\section{Notes}

${ }^{1}$ We would like to thank David Falk and Sara Edvinsson at the Centre for Civil Society Studies at Stockholm School of Economics, and Tino Schöllhorn at University of Mannheim, for valuable research assistance.

${ }^{2}$ The visual depiction of the data in this section is based on the Fruchterman-Reingold algorithm, which interprets a relation between two nodes as a force pulling these two nodes together. As nodes typically have many relations, they are pulled into various directions. The algorithm identifies the optimal solution where the different strengths are balanced. In a network that is characterised by many nodes and relations, more than one optimal solution may exist. Hence, each time the algorithm is started, solutions might differ. As there are different solutions, we do not visualise the data using Euclidean distances. Instead, the number of ties to get from one node to another node is a distance that is stable for all visualisations. For example, if two nodes are connected with each other, they are likely to be positioned in proximity to each other in each graph, but not necessarily with the exact same Euclidean distance.

\section{References}

Andonova, LB, Mitchell, RB, 2010, The rescaling of global environmental politics, Annual Review of Environment and Resources 35, 255-82

Ansell, C, Gash, A, 2008, Collaborative governance in theory and practice, Journal of Public Administration Research and Theory 18, 543-71

Avant, D, Finnemore, M, Sell, SK (eds), 2010, Who governs the globe?, Cambridge: Cambridge University Press

Beech, J, 2009, Policy spaces, mobile discourses, and the definition of educated identities, Comparative Education 45, 3, 347-64

Beech,J,2011, Global panaceas, local realities: International agencies and the future of education, Frankfurt on the Main: Peter Lang

Boli,J,Thomas, GM, 1997,World culture in the world polity:A century of international non-governmental organization, American Sociological Review 62, 171-90

Boli,J,Thomas, GM (eds), 1999, Constructing world culture: International nongovernmental organizations since 1875, Stanford, CA: Stanford University Press

Boulton, G, Lucas, C, 2008, What are universities for?, Leuven: League of European Research Universities

Bourdieu, P,1977, Outline of a theory of practice, Cambridge: Cambridge University Press Bourdieu, P, 1984, Distinction: A social critique of the judgement of taste, Cambridge, MA: Harvard University Press

Brunsson, N, Ahrne, G, 2008, Meta-organizations, Cheltenham: Edward Elgar

Brunsson, NB Jacobsson, B, 2000, A world of standards, Oxford: Oxford University Press Collini, S, 2012, What are universities for?, London: Penguin

DiMaggio, PJ, Powell, WW, 1983, The iron cage revisited: Institutional isomorphism and collective rationality in organizational fields, American Sociological Review 48, 2, 147-60

Djelic, M-L, Sahlin-Andersson, K (eds), 2006, Transnational governance: Institutional dynamics of regulation, pp 1-28, Cambridge: Cambridge University Press 
Djelic, M-L, Sahlin, K, 2011, Reordering the world: Transnational regulatory governance and its challenges, in L Faur (ed) The Oxford Handbook of Governance, pp 745-58, Oxford: Oxford University Press

Drori, GS, Meyer, JW, Hwang, H, 2009, Global organization: Rationalization and actorhood as dominant scripts, in R Meyer, K Sahlin, M Ventresca, P Walgenbach (eds) Research in the sociology of organizations: Institutions and ideology, 27, pp 17-43, Bingley: Emerald

Drori, GS, Delmestri, G, Oberg, A, 2012, Branding the university: Relational strategy of identity construction in a competitive field, in L Engwall, P Scott (eds) Trust in higher education institutions, London: Portland Press

Finnemore, M, 1993, International organization as teachers of norms: The United Nations educational, scientific, and cultural organization and science policy, International Organization 47, 567-97

Finnemore, M, Sikkink, K, 1998, International norm dynamics and political change, International Organization 52, 4, 887-917

Fligstein, N, McAdam, D, 2011, Toward a general theory of strategic action fields, Sociological Theory 29, 1, 1-26

Fligstein, N, McAdam, D, 2012, A theory of fields, Oxford: Oxford University Press

Frank, DJ, Meyer,JW, 2007, University expansion and the knowledge society, Theory and Society 36, 4, 287-311

Hedmo, T, 2004, Rule-making in the transnational space: The development of European accreditation of management education, $\mathrm{PhD}$ dissertation, Uppsala: Uppsala University

Hedmo, T, Sahlin-Andersson K, 2006, The evolution of a European governance network of management education, in M Marcussen, J Torfing (eds) Democratic network governance in Europe, Basingstoke: Palgrave MacMillan

Hedmo, T, Sahlin-Andersson, K, Wedlin, L, 2006, Is a global organizational field of higher education emerging? Management education as an early example, in G Krücken, A Kosmütsky, M Torka (eds) Towards a multiversity? Universities between global trends and national traditions, Bielefeld:Transcript Verlag

Krücken, G, Meier, F, 2006, Turning the university into an organizational actor, in GS Drori, JW Meyer, H Hwang (eds) Globalization and organization: World society and organizational change, Oxford: Oxford University Press

Krücken, G, Kosmütsky, A, Torka, M (eds) 2007, Towards a multiversity? Universities between global trends and national traditions, Bielefeld:Transcript Verlag

Lewin, K, 1951, Field theory in social science; selected theoretical papers, D, Cartwright (ed), New York: Harper \& Row

Maassen, P, Olsen, JP, 2007, University dynamics and European integration, Springer: Dordrecht

Marcussen, M, 2000, Ideas and elites, Denmark: AAlborg University Press

Marcussen, M, 2004, OECD governance through soft law, in U Mörth (ed) Soft law in governance and regulation, pp 103-28, Cheltenham: Edward Elgar

Marcussen, M, Torfing, J, 2007, Democratic network governance in Europe, Basingstoke: Palgrave Macmillan

Martin, JL, 2003, What is field theory?, American Journal of Sociology 109, 1-49

Meyer, J, 1996, Otherhood: The promulgation and transmission of ideas in the modern organizational environment, in B Czarniawska, G Sevón (eds) Translating organizational change, pp 241-52, de Gruyter Studies in Organization 
Meyer, JW, Bromley, P, 2013, The worldwide expansion of 'organization', Sociological Theory 31, 4, 366-89

Meyer,JW, Rowan, B, 1977, Institutionalized organizations: Formal structure as myth and ceremony, American Journal of Sociology 83, 2, 340-63

Mohr, JW, 2005, Implicit terrains: Meaning, measurement, and spatial metaphors in organizational theory, in M Ventresca, J Porac (eds) Constructing industries and markets, New York: Elsevier.

Mörth, U, 2004, Soft law in governance and regulation, Cheltenham: Edward Elgar

O’Brien, R, Goetz, AM, Scholte, JA, Williams, M, 2000, Contesting global governance: Multilateral economic institutions and global social movements, Cambridge: Cambridge University Press

Perrow, C, 1991, A society of organizations, Theory and society 20, 6, 725-62

Perrow, C, 2002, Organizing America: Wealth, power, and the origins of corporate capitalism, Princeton, NJ: Princeton University Press

Ramirez, FO, 2006, The rationalization of universities, in M-L Djelic, K SahlinAnderson (eds) Transnational governance: Institutional dynamics of regulation, Cambridge: Cambridge University Press

Ramirez, FO, 2010, Accounting for excellence: Transforming universities into organizational actors, in VD Rust, LM Portnoi, SS Bagely (eds) Higher education, policy, and the global competition phenomenon, New York: Palgrave Macmillan

Ramirez, FO, 2012, The world society perspective: Concepts, assumptions, and strategies, Comparative Education 48, 4, 423-39

Risse, T, 2012, Governance in areas of limited statehood, in L Faur (ed) The Oxford handbook of governance, pp 699-716, Oxford: Oxford University Press

Reuter, M, Wijkström, F, Meyer, M, 2014, Who calls the shots? The real normative power of civil society, in M Freise, T Hallmann (eds) Modernizing democracy: Associations and associating in the 21st century, New York: Springer

Sahlin, K, 2013, Global themes and institutional ambiguity in the university field: Rankings and management models on the move, in GS Drori, M Höllerer, P Walgenbach (eds) Global themes and local variations in organization and management: Perspectives on glocalization, New York: Routledge

Sahlin, K, Wedlin, L, 2008, Circulating ideas: Imitation, translation and editing, in R Greenwood, C Oliver, K Sahlin, R Suddaby (eds) Handbook of organizational institutionalism, Los Angeles, CA: Sage

Sahlin-Andersson, K, 1996, Imitating by editing success: The construction of organizational fields, in B Czarniawska, G Sevón (eds) Translating organizational change, pp 69-92, Berlin: Walter de Gruyter

Sahlin-Andersson, K, Engwall, L, 2002, Carriers, flows, and resources of management, in K Sahlin-Andersson, L Engwall (eds) The expansion of management knowledge: Carriers, flows, and sources, pp 3-32, Stanford, CA: Stanford University Press

Selznick, P, 1949, TVA and the Grass Roots, Berkeley, CA: University of California Press Stoker, G, 1998, Governance as theory: Five propositions, International Social Science Journal 50, 17-28

Tallberg, J, Sommerer, T, Squatrito, T, Jönsson, C, 2013, The opening up of international organizations: Transnational access in global governance, Cambridge: Cambridge University Press

Torfing,J, 2012, Governance networks, in L Faur (ed) The Oxford handbook of governance, pp 99-112, Oxford: Oxford University Press 
Union of International Associations, 2014, Yearbook of international organizations, www. uia.be/yearbook-international-organizations-online

Wijkström, F, 2011, 'Charity speak' and 'business talk':The on-going (re)hybridization of civil society, in F Wijkström, A Zimmer (eds) Nordic civil society at a cross-roads: Transforming the popular movement tradition, Baden-Baden: Nomos

de Wilde, P,Zürn, M, 2012, Can the politicization of European integration be reversed, Journal of Common Market Studies 50, 1, 137-53

Zürn, M, Binder, M, Ecker-Erhardt, M, 2012, International authority and its politicization, International Theory 4, 1, 69-106

\begin{tabular}{|l|l|l|}
\hline Appendix: Core intermediaries in the field & & \\
\hline Cluster No 1: 'Europe' (top ten intermediaries) & Website and 'centrality' \\
\hline European University Association & & 50 \\
\hline
\end{tabular}


International Association of Universities

iau-aiu.net

Academic Cooperation Association

aca-secretariat.be $\quad 32$

Nuffic

nuffic.nl 30

European Association for Quality Assurance in Higher

enqa.eu

Education

European Association for International Education

eaie.org

International Network for Quality Assurance

inqaahe.org

Agencies in Higher Education

World Education Services

wes.org

Observatory on Borderless Higher Education

obhe.ac.uk

European Consortium for Accreditation

ecaconsortium.net

\section{Cluster No 2: 'UK' (top intermediaries)}

British Council

britishcouncil.org $\quad 38$

Universities UK

universitiesuk.ac.uk 18

The Higher Education Academy

heacademy.ac.uk 16

The Association of Commonwealth Universities

acu.ac.uk

\begin{tabular}{|c|c|c|}
\hline Cluster No 3: 'Germany' (top intermediaries) & & \\
\hline Max-Planck-Gesellschaft & mpg.de & 24 \\
\hline Deutsche Forschungsgemeinschaft & dfg.de & 22 \\
\hline Informationsdienst Wissenschaft & idw-online.de & 18 \\
\hline Deutsches Institut für Wirtschaftsforschung & diw.de & 17 \\
\hline Cluster No 4: 'US etc' (top intermediaries) & & \\
\hline Institute of International Education & iie.org & 35 \\
\hline American Council on Education & acenet.edu & 26 \\
\hline EDUCAUSE & educause.edu & 20 \\
\hline Research Papers in Economics & repec.org & 19 \\
\hline NAFSA: Association of International Educators & nafsa.org & 18 \\
\hline Association of American Colleges \& Universities & aacu.org & 18 \\
\hline Influential organisations without obvious clust & mbership & \\
\hline World Bank & worldbank.org & 73 \\
\hline $\begin{array}{l}\text { Deutsche Gesellschaft Für Internationale } \\
\text { Zusammenarbeit }\end{array}$ & giz.de & 22 \\
\hline Hochschulrektorenkonferenz & hrk.de & 18 \\
\hline
\end{tabular}

